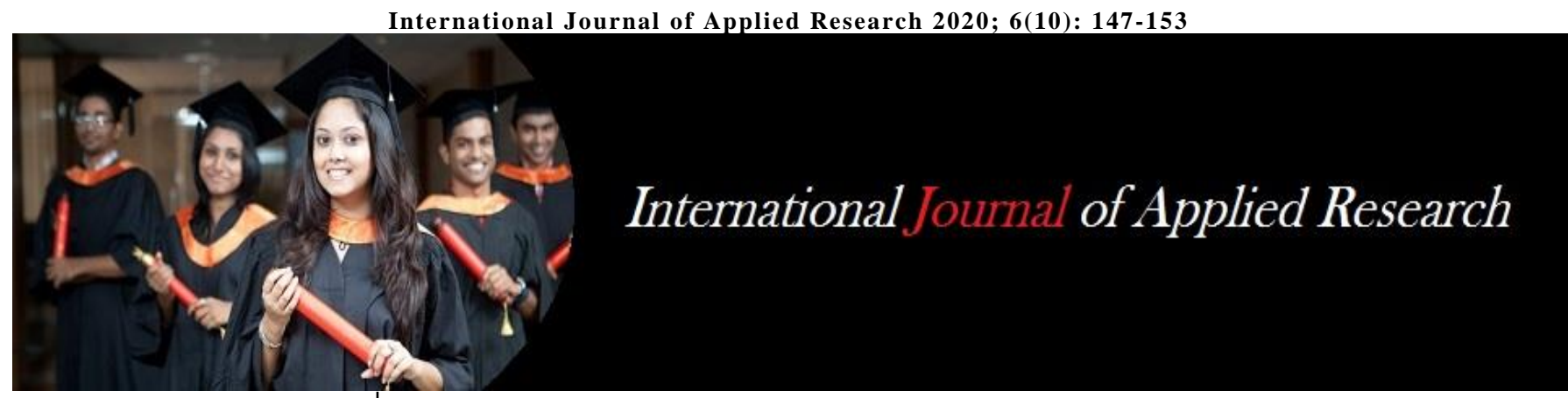

ISSN Print: 2394-7500 ISSN Online: 2394-5869 Impact Factor: 5.2 IJAR 2020; 6(10): 147-153 www.allresearchjournal.com Received: 26-08-2020 Accepted: 29-09-2020

Tesfaye Legesse Gebreyohannis (Msc), Lecturer at Sport

Science Department of Wollo University, Dessie, Ethiopia
Corresponding Author: Tesfaye Legesse Gebreyohannis (Msc), Lecturer at Sport Science Department of Wollo University, Dessie, Ethiopia

\section{Assessment of the determinants of accessibility of sport facilities and equipment: the case of Dessie city administration}

\section{Tesfaye Legesse Gebreyohannis}

DOI: $\underline{\text { https://doi.org/10.22271/allresearch.2020.v6.i10c.7261 }}$

\begin{abstract}
The purpose of the study was to assess the Determinants of accessibility of Sport facilities and equipment the Case of Dessie City administration. The data was collected through questionnaire, interview and observation method from the list of sampling frame, a total of 3939 respondents participated as the source of data by using simple random sampling and purposive sampling methods. The design of the study was descriptive survey research. The data collected were organized, analyzed and interpreted by using descriptive statics. The findings indicated that budget, low efforts, role and capability of sport administrators to mobilize the community, problem of sport facilities ownership and unable to the surrounding opportunities and less protection of the community for sport facilities resources are the determinants of availability of sport facilities and equipments. Consequently, it was concluded that less annual sport facilities budget, less capability of sport administrators to mobilize the surrounding community in generating income, sport facilities ownership issues and surrounding opportunities are limiting factor of the availability of sport facilities and equipments in Dessie city administration. Thus, it was recommended that an appropriate budget has to be allocated for the availability of sport facilities and equipments in accordance with the annual activity plan of the sub cities, the concerned bodies have to build the capacity of the sport administrators to work with surrounding community in generating income for the development of sport activities and sport facilities fulfilments, the concerned body has to give a due attention for the protection of sport facilities and the community itself will protect the resources there.
\end{abstract}

Keywords: sport facilities, sport equipments, sport administration

\section{Introduction}

Sport embraces much more than traditional team games and competition. Sport means all forms of physical activity which, through casual or organized participation, aim at expressing or improving physical fitness and mental well-being, forming social relationships or obtaining results in competition at all levels, (Dawson. A. Dejionghe, T. and Downward, 2011) ${ }^{[6]}$. According to Higham, J. and Hinch, T. (2003) ${ }^{[11]}$, Sport development is a process whereby effective opportunities, processes, systems and structures are set up to enable and encourage people in all or particular groups or areas to take part in sport or recreation or to improve their performance to whatever level they desire. A sport facilities is a place where the whole necessary sport and social affairs and functions can take place there; in order to use high potentially of these equipments, the availability of these are essential for the whole parts of a community, (Cindy, K., Jeffrey, G. and Petersen, 2006) ${ }^{[5]}$.

Sports facilities and equipment are "laboratories" for Physical Education where games are performed or played and consequently facilities and equipment are important for achievement of goals of Physical Education and sports, (Nteere, J.S. and Rintaugu, E.G.; 2011) ${ }^{[18]}$.

The benefits of having a sports facility in a community are many from a shared sense of public pride to increased job opportunities to enhanced real estate values but perhaps surprisingly, immediate profitability is not among them. The availability of a wide range of good quality and reasonably priced sporting equipment is an important factor in the development of sport. In this regard working in collaboration with the National Sporting Organizations and Sport Dealers Association, Government will try to keep sport equipment 
at an affordable cost in order to facilitate Total Participation in Sport and High Performance Sport, (Ministry of Sport and Youth Affairs, 2002) ${ }^{[17]}$.

A number of researchers focused on in the development of sport related with sport facilities and equipment. as the literature shows Sports facilities and equipment are fundamental to sports development and achievements globally. The availability of a wide range of good quality and reasonably priced sporting equipment is an important factor in the development of sport (Ministry of Sport and Youth Affairs, 2002) ${ }^{[17]}$.

In the developed world, sports facilities and equipment of the appropriate standard are available of promote the athletes performance, (Ojeme, E.O. 2000) ${ }^{[19]}$. If the vision of once country to be achieved the people of that country must be able to use a full rang accessible sports facilities of an appropriate standard at affordable price, (Delva and Tamerman 2007) ${ }^{[7]}$. Any established sports clubs or other groups using the sports facilities at present to establish their views and potential to help deliver the draft objectives determined in the initial appraisal, (Scottish Sports Council, 2000) ${ }^{[8]}$.

According to the Diejomaoh, E.o., Akarah, E. and Tayire, O.F. (2015) ${ }^{[8]}$ research result show that, Low level of provision of sports facilities and equipment could mean that sports in that area standing on a weak foundation in the absence of meaningful grassroots sports development. Sport facilities, sport wear and equipment, as well as the lack of trained personnel in the field must have made the problem more complex. As incorporated in the sport policy document (2004), the policy out lines clearly selected goal, strategies and means as to how the problems could be addressed. It further defines to what point sport should be directed, what, how, where, who, why to train, who to be a trainer at different levels, decisions as to organization, facilities and administrative arrangements as well as coordination among its several elements. In spite of all these frameworks, there seems to be an immense gap between what is written in black and white and actually practiced on the ground, ever since the policy has been in to action, i.e., the question of hands-on job. Apparently, sport in all countries is changing with time, but not uniformly at all, as the gap in resource between wealthy and poor countries is growing. It is also indicated at these outsets that; the availability of quality sport facility is necessary for proper training. Where this doesn't exist, it is difficult to achieve the intended objectives set a head of time (Judith G.L.1998) ${ }^{[14]}$. Sports facilities often provide considerable employment and training opportunities in both their construction and operation. The availability of good quality and affordable sports and outdoor activity facilities can contribute to visitors' enjoyment of the borough as a destination. In particular, water sports are a significant attraction for the borough, (Borough, P. and Weymouth, 2014) ${ }^{[3]}$. Having a good installation of sports equipment near your home is always a big plus. Seniors may find in sport a way to control your weight and a way to maintain a healthy life, for children and teens sport can be a way of socialization and integration. Therefore it is especially important to have sports equipment in your city, in your neighbourhood, in your town, ultimately, near your home, (MRiera 2016) ${ }^{[16]}$.

In the study area there are 6 playing fields from thirty (13) sub cities. Which are found at Hotie, Gerado, Tita, Menafesha, Buwanebuha, and Signo Bilen.

\section{Objectives of the study}

The main objective of this study is to investigate the Determinants of accessibility of Sport facilities and equipment the Case of Dessie City administration.

The Specific objective of the study includes:

- To identify the prioritized determinants of accessibility sport facilities and equipments

- To assess the availability of sponsoring organization and interest people for fulfilling sport facilities Dessie city administration

- To identify role, effort and competences of sport employees of Dessie city administration to mobilize the society to fulfil sport facilities and equipment

- To check legal ownership and management issue of sport fields in Dessie City administrators

\section{Research Question}

The research undertaken to answer the following research questions

- What are the major factors that affect the accessibility of sport facilities and equipment in the case of Dessie city administration

- It there sponsoring organization and interested people for fulfilling sport facilities and equipments in Dessie city administration?

- Is there sport employees role, effort and competences of sport employees of Dessie city administration to mobilize the society and organization to fulfil sport facilities and equipment

- Does sport fields have legal ownership and get proper management from Dessie City administration office

\section{Research Methodology 4.1 Description of the study area}

The study is planned to be conducted at Dessie city administration. It is the capital city of south Wollo Zone. The town founded in 1885 E.c and lies on the intersection of $11^{0} 8^{\prime} \mathrm{N}$ latitude and $39^{\circ} 38^{\prime} \mathrm{E}$ longitude. The relative location is about $401 \mathrm{~km}$ North of Addis Ababa on Addis- Mekele highway. The average elevation of the town ranges from 2400 to 2800 meter above sea level. The town is bounded and squeezed by a series of ranges and escarpments with rugged surfaces between the cliffs of Tossa and Azuwa, and Borkena River divides this basin in to two parts. With respect to the climatic conditions of Dessie, it mostly falls within "Dega" agro climatic zone with an average monthly minimum and maximum temperature of $12.37^{\circ} \mathrm{c}$ and $27.27^{\circ} \mathrm{c}$ respectively.

The city has above 151,094 (census, 2007) number of population. Dessie city administration is one of popular area regarding to sport participation and produce a number of sport clubs from these club players enters into Ethiopian national league.

\subsection{Research Design}

This study plans to assess the factor that limited the accessibility of sport facilities and Equipments in Dessie city administration and suggesting strategies that promote accessibility of sport facilities and equipment. Hence descriptive survey research design was used for the study to achieve the set objectives and to answer the research question. Because of descriptive survey is preferred over other design as it enables to make investigations with predictions, narration of events, and drawing of conclusions 
based on the information obtained from relatively large and representative samples of the target population (Kothari, 2007) ${ }^{[15]}$. Moreover, Sekaran (2003) ${ }^{[21]}$ described that a descriptive study is undertaken in Order to ascertain and be able to describe the characteristics of the variables of interest in a Situation. In this research both quantitative and qualitative research approach was used, in order to collected and analyses data.

\subsection{Source of data}

The current study is designed to assess the factors that determine accessibility of sport facilities and equipments in once city administration. Hence, data for this study was collect both from secondary sources and primary sources of data through document review and structured questionnaire that was help to gather their opinion. Secondary data was used particularly analysis the trends of the budget allocations in the city administration for the fulfilment of sport facilities and equipments. And the researcher gather data or information collect through books, literature, document and internet was used secondary source of data.

\subsection{Population of the study}

In the current study, Data was collected from sport administrators and officers, sub city administrators and sport participants. Hence, the target population of this study is those segments of the population in Dessie city administration. Considering the administrative division of the sport sector in the town there are 13 sub cities under which there is one sport administrator and one sport officers and also one sub city administrator in each sub cities. These are in total 39. Furthermore, according to Dessie city Administration sport and youth office information, there are an estimated 3900 number of active sport participants. So the researcher also considers these data as target population. Therefore, for the current study the size of the population in addition to Sport administrator, officer and sub city Leaders will be 3939 .

\subsection{Sample Size and sampling techniques}

Considering the fact that the study was covers all sport administrators, officers, sub city administrators as well as sport participants in Dessie city administration, not all the respondents can be included in the study in order to collect data required for the analysis. It is thus significant to draw a sample from the population. For this study, samples are determined as follows using Taro Yamani's formula for selecting sport participants.

$$
\mathrm{n}=\frac{\mathrm{N}}{1+\mathrm{N}(\mathrm{e})^{2}}
$$

Where $\mathrm{n}=$ sample size

$\mathrm{N}=$ population size

$\mathrm{E}=$ Level of significance (acceptable error/limit 5\%)

$1=$ constant

$$
\frac{3939}{1+3939(0.05)^{2}}=363
$$

The number of respondents of sport participants for this research, therefore, was 363. The researcher was selected sport participants from the population through simple random sampling technique by taking individuals who was come in the field while the researcher goes there for data collection. Likewise, these participants was from each sub cities in an equal proportion that means 28 sport participant respondents from each sub cities. And also the researcher was used purposive sampling techniques to select all sport administrators, sport officers and sub city administrators. Therefore the researcher selects all 13 sport administrators, 13 officers and 13 sub city administrators were participating in the study.

\subsection{Data collection Techniques}

For the purpose of this research, and in order to achieve the objectives the researcher used both primary and secondary data. The secondary data was contributed toward the formation of background information, needed by both the researcher in order to build constructively the study and the reader to comprehend more thoroughly the research outcome. So in order to collect the necessary data to conduct the study, the researcher was used three data collection tools. These are questionnaire, interview and observation

\subsubsection{Questionnaire}

The understanding of the sport participants and sport experts about situations of sport facilities and equipments in the study area were surveyed through standardized questionnaire to determine the factors that affect the accessibility of sport facilities and equipments. Questionnaire is a systematic compilation of questions that are submitted to a sampling of population from which information is desired. Cohen (1989) [4] defines a questionnaire as a self-report instrument used for gathering information about variables of interest to an investigation. Questionnaires are employed to generate both quantitative and qualitative data relevant to collect the information from sport officers, sport administrators, sub city administrators and sport participants (Athletes) of the sample population.

In order to achieve the set objectives of the currents study, questionnaire in the variables of interest are prepared in the form of five point Lickert scales that was measure respondents level of agreement on the factors affecting the accessibility of sport facilities and equipments. Because of Many researchers prefer to use a Lickert type scale because it's very easy to analyze statistically. (Jackson, 2009, p. 89) [12].

Furthermore, in order to improve the reliability of the questionnaire, questionnaire was administered after translation into Amharic language. In fact, for more reliability check-up of the instrument/questionnaire a pilot study was conducted by collecting data from 10 sport participants and 3 sport administrators' respondents.

\subsubsection{Interviews}

Structured and semi structured interview was also held with Dessie city administration sport and youth office head in order to collect in-depth data for the situation of the town accessibility of sport facilities and equipments. An interview is the most versatile and productive method of communication, enabled spontaneity, and also provided with: "The skill of guiding the discussion back to the topic outlined when discussions are unfruitful while it has the disadvantages of being very costly time consuming and can introduce bias through desires of the respondent to please the Interviewer", (Aaker \& Day, 1990) ${ }^{[1]}$. There were 13 sport administrators who were interviewed for this study. 


\subsubsection{Observation}

The researcher prepared an observational checklist and assess the real information would be known and check their own questions that were fulfilled their realities. Observation was used to collect data from the actual condition of sport facilities and equipments include accessible of sport facilities and equipments.

\subsection{Methods of data collection}

In conducting the current study, the following relevant procedures were used. After designing the research instruments, (questionnaire, interview, observation checklist), organize them, the research sites and sample size of participants were identified, Then the researcher asking permit ion from each sub cities administrator and sport expert and participant(athletes). Giving orientation about the research intention for the participants clearly and their response would be kept in confidential. Date and times of contact were determined and questionnaires were distributed to selected sport expert and sport participant (Athletes). The interview session followed with each sub city sport administrator. Then, observation of the sport facilities and equipments availability and services the first step in data collection and used to gaining first hand information of the facilities and equipments

\subsection{Data Analysis Methods}

In conducting the current study, the following relevant procedures and techniques was used to analysis the collected data as well as to achieve the set objectives. After arranging the data collected through questionnaire (i.e multiple choice and Likert scale) for analysis, descriptive statistics was employed for the detail statistical analysis. As far as data analysis is concerned, both qualitative and quantitative approaches were employed. Qualitative method was used to provide detail explanation of the data to help the researcher to explore and discover inherent facts, while quantitative approaches was quantifying data generated in terms of frequency and percentage by using SPSS software version 20.

\section{Result}

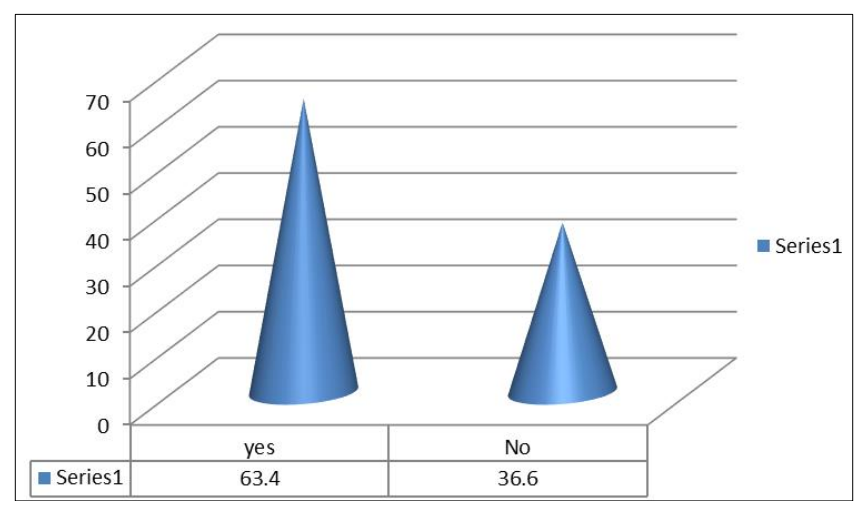

Fig 1: Sport fields ownership Issue

The percentage of sport fields with Site ownership issues are illustrated in the above figure. As indicated in the above figure, $36.6 \%$ of sport fields have plan. But $63.4 \%$ of sport fields have no plan. So this indicates the majority of sport fields in Dessie city have no legal ownership. More particularly, the interview result indicated that three sport fields of which the two are in Hote sub city and the other one in Arada sub city, plan and legal ownership. This issue has its own contribution for the fulfilment of sport equipments and construction of sport fields with having a sense of ownership.

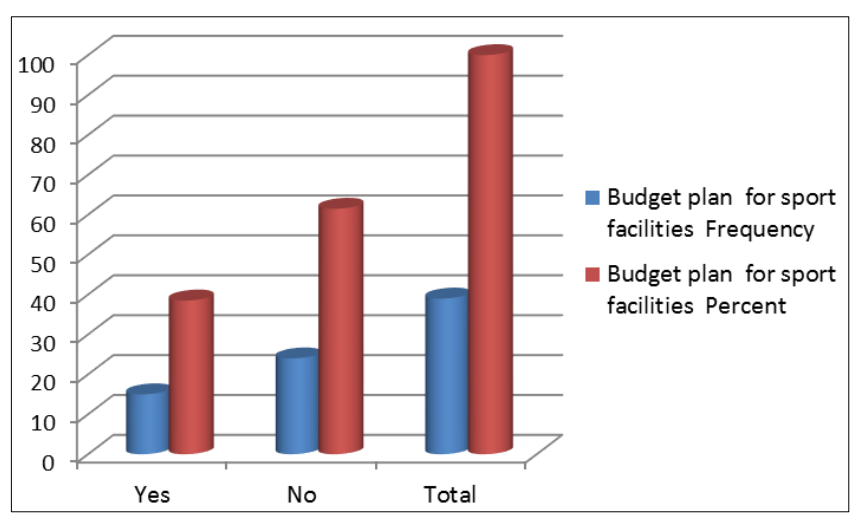

Fig 2: Existence of Budget plan for sport facilities

As shown in the above figure, majority of the respondents which consists of $61.5 \%$ of the total respondents responded that most of sport administrative offices don't have a budget allocated for the fulfilment of sport facilities and equipments. In fact, the other smaller groups of the respondents $(38.5 \%)$ replay conversely that there is a budget plan for fulfilment of sports facilities. From this it can be concluded that there is no sufficient financial budget allocated for the improvement and construction of sport facilities in the town. It is also reported in the interview with officials that even maintenance of the existing sport facilities is undertaken only when there is an official event at regional or national level once in many years. Hence, non-allocation of financial budget is one factor for the fulfilment of sport facilities and equipments in the town.

Table 1: Sport administrator, officer and sub city Leader on Allocation of budget for sport equipments

\begin{tabular}{|l|c|c|c|c|c|}
\hline \multicolumn{2}{|c|}{$\begin{array}{c}\text { Allocation of budget } \\
\text { for sport equipments }\end{array}$} & Frequency & Percent & $\begin{array}{c}\text { Valid } \\
\text { Percent }\end{array}$ & $\begin{array}{c}\text { Cumulative } \\
\text { Percent }\end{array}$ \\
\hline \multirow{3}{*}{ Valid } & Yes & 6 & 15.4 & 15.4 & 15.4 \\
\cline { 2 - 6 } & No & 33 & 84.6 & 84.6 & 100.0 \\
\cline { 2 - 6 } & Total & 39 & 100.0 & 100.0 & \\
\hline
\end{tabular}

The respondents were asked about the availability of budget for the fulfilment of sport equipments in the city. Accordingly, as indicated from the table, majority of the respondents which compromises of $84.6 \%$ of the total respondents reported that there is no allocation of budget for the fulfilment of sport equipment beyond the fulfilment of the sport facilities. In contrary, the remaining fewer proportion of the respondents $(15.4 \%)$ acknowledges the allocation of budget for the fulfilment of sport equipments in their respective sub cities. Even, those who reported the existence of allocated budget in their respective sub cities reported $100 \%$ that the allocated budget is insufficient to fulfil sport facilities and equipment. In general, it can be concluded that one of the determinant factors for the fulfilment of both sport facilities and equipments in the town is non allocation of sufficient budget at sub city level. Due to that sub cities faced hardship to improve as well as repair sport facilities and equipments at their respective sub cities level. 
Table 2: The role, competences and efforts of sport officers and administrators in fulfilling sport facilities

\begin{tabular}{|c|c|c|c|c|c|c|}
\hline & Variables & \begin{tabular}{|c|} 
Very \\
High \\
\end{tabular} & High & Satisfactory & Low & $\begin{array}{l}\text { Very } \\
\text { Low }\end{array}$ \\
\hline 1 & The effort of officers in encouraging business man to support the business for sport facilities & $4.0 \%$ & $12.1 \%$ & $30.0 \%$ & $28.5 \%$ & $25.4 \%$ \\
\hline 2 & The competency of officers and sport administrator in finding out a fund for sport facilities & $4.3 \%$ & $14.0 \%$ & $29.5 \%$ & $30.7 \%$ & $21.5 \%$ \\
\hline 3 & $\begin{array}{l}\text { The efficiency of officers and administrators in managing, controlling and properly use for } \\
\text { sport facilities }\end{array}$ & $6.6 \%$ & $21.1 \%$ & $31.5 \%$ & $22.5 \%$ & $18.2 \%$ \\
\hline 4 & $\begin{array}{l}\text { The awareness creation by the sport officers and administrators for sponsoring bodies and } \\
\text { society for fulfilment of sport facilities }\end{array}$ & $3.4 \%$ & $10.3 \%$ & $27.5 \%$ & $37.2 \%$ & $21.5 \%$ \\
\hline
\end{tabular}

The survey result in the above table indicated that majority of the respondents which comprise of $53.9 \%$ agreed that, the effort of Sport administrators and officers in encouraging business man to support the business for sport facilities fulfilment is insufficient. Whereas, $30 \%$ of the respondents replied as the effort of sport administrators and officers in encouraging business man to support the business for sport facilities is sufficient. The remaining fewer proportion of respondents $(16.1 \%)$ believes that sport administrators and officers exert higher effort for the fulfilment of sport facilities in their respective Sub-cities. These all level of opinion implies that the effort of sport administrators and officers to the accessibility of sport facilities for sport participants is not as it is expected from them.

Regarding to how is the competency of officers and sport administrator in finding out a fund for sport facilities? To respond for this, question a survey were conducted by asking respondents to state their level of believe on the sufficiency of the competency of officers and sport administrator in finding out a fund for sport facilities. The survey results that $18.3 \%$ of the respondents believe that the competency of officers and sport administrator in finding out a fund for sport facilities is above sufficiency. On the contrary $29.5 \%$ of the respondents doubt the competency of officers and sport administrator in finding out a fund for sport facilities is sufficient. In fact, there are also $52.2 \%$ of the respondents believe as the competencies of the sport administrators below sufficient on the issues discussed above. It can also drive a conclusion from the above survey result that sport administrators are not as such the competent enough in finding out a fund for sport facilities.

How is the efficiency of officers and administrators in managing, controlling and properly use for sport facilities?
To respond for this, question a survey were conducted by asking respondents to state their level of believe on the efficiency of officers and sport administrator in order to managing, controlling and properly use for sport facilities. The survey results that $27.7 \%$ of the respondents believe that the efficiency of officers and sport administrator in order to managing, controlling and properly use for sport facilities is above sufficiency. On the contrary the majority of the respondents $40.7 \%$ doubt the efficiency of sport officers and administrator in order to managing, controlling and properly use for sport facilities is below sufficient. In fact, there are also $31.5 \%$ of the respondents believe as the efficiency of the sport administrators and sport officers insufficient on the issues discussed above. It can also drive a conclusion from the above survey result that sport administrators and sport officers are not efficiency in order to managing, controlling and properly use for sport facilities.

The survey result in the above table question number four, indicated that majority of the respondents which comprise of $58.7 \%$ agreed that the awareness creation by the sport officers and administrators for sponsoring bodies and society for sport facilities is insufficient. Whereas, $27.5 \%$ of the respondents replied as the awareness creation by the sport officers and administrators for sponsoring bodies and society for sport facilities is sufficient. The remaining fewer proportion of respondents $(13.7 \%)$ believes that sport administrators and officers exert higher effort for the fulfilment of sport facilities in their respective Sub-cities. These all level of opinion implies that the effort of sport administrators and officers to the accessibility of sport facilities for sport participants is not as it is expected from them.

Table 3: Existence of Opportunities in Fulfilling Sport Facilities and Equipments

\begin{tabular}{|c|c|c|c|c|c|c|c|c|}
\hline & Variables & $\begin{array}{c}\text { Very } \\
\text { High }\end{array}$ & High & $\begin{array}{c}\text { Sum Above } \\
\text { Sufficient }\end{array}$ & Sufficient & Low & $\begin{array}{c}\text { Very } \\
\text { Low }\end{array}$ & $\begin{array}{c}\text { Sum Below } \\
\text { Sufficient }\end{array}$ \\
\hline 1 & $\begin{array}{c}\text { The society interest for sport in order to } \\
\text { expansion of sports facilities }\end{array}$ & $15.2 \%$ & $27.8 \%$ & $43.00 \%$ & $30.7 \%$ & $17.2 \%$ & $9.1 \%$ & $26.30 \%$ \\
\hline 2 & $\begin{array}{c}\text { The availability of sponsoring bodies for } \\
\text { expanding sport facilities }\end{array}$ & $4.6 \%$ & $18.3 \%$ & $22.90 \%$ & $29.5 \%$ & $30.7 \%$ & $16.9 \%$ & $47.60 \%$ \\
\hline
\end{tabular}

The survey result in the above table question number 2 indicated that which comprise of $26.30 \%$ of the respondents agreed that the society interest for sport in order to expansion of sports facilities is insufficient. Whereas, $30.70 \%$ of the respondents replied as the society interest for sport in order to expansion of sports facilities is sufficient. The remaining majority of respondents $(43 \%)$ believe that the society interest for sport in order to expansion of sports facilities is above sufficient. These all level of opinion implies that the society interest for sport in order to expansion of sports facilities is above sufficient.

The other determinant factors for the fulfilment of sport facilities as well as sport equipments are the availability of sponsors in the city. Sponsor is the life blood of sports. Accordingly, the survey results indicated that that $22.9 \%$ of the respondents believe that availability of sponsoring bodies for expanding and fulfilling sport facilities is above sufficiency. On the contrary the majority of the respondents $47.6 \%$ non availability of sponsoring bodies for expanding sport facilities is below sufficient. In fact, there are also $29.5 \%$ of the respondents believe as availability of sponsoring bodies for expanding sport facilities in sufficient on the issues discussed above. It can also drive a conclusion from the above survey result that sponsoring bodies are not available for expanding sport facilities in Dessie city administration 


\section{Discussion}

Budget is important for building new, and improving existing sport and active recreation facilities in one country as an enabler for increasing access and availability for physical activity and community wellbeing. If you're considering opening up a sports facility, recreation centre, or community centre, you will have to do a fair amount of budget planning. According to the responses of the research participants, there is a great problem to allot sufficient budget to fulfil sport facilities and equipments in Dessie city administration. As investigated in the current research, it can be respondents responded that, there is no sufficient allotted fund $(84.6 \%)$ for sport facilities and equipments in Dessie city administration in general and in sub cities level in particular. Likewise, the fund raised to finance the fulfilments of sport facilities and equipments is very low due to the lower role, effort and capability of sport officers and administrators. Regard to this as Adedeji (1990) [2] stressed that budgeting as the determination, allocation, and deployment of funds and facilities for the services of the school in accordance with the schools educational needs and objectives. According to John Street (1999), budgeting can be done not only for sport organizations but also the whole of government or for individual units of the larger organization.

Sponsoring bodied has a great role to alleviate the problem of budget and to fulfil sport facilities and equipments require by the sport community. So, they are the life blood of sport development in general. To mobilize sponsoring organization and sport lover community for funding is one of the main role and duties of sport leaders and officers of Dessie city administration youth and sport office. In this regard there are many organization and sport lovers in Dessie city administration that can support budget and other sport facilities. So as the study reveals, the availability of sponsoring bodies for expanding sport facilities is moderate (i.e sufficient and above sufficient, 52.40\%) where as the society interest for sport for expansion and fulfil of sports facilities is also in an excellent position( i.e sufficient and above sufficient, $73.70 \%$ ). But as the study reveals there is very low of sport leader and officers to mobilizing the interested group and organization in the study area to get budget. This is due to the fluctuation of commitment of the surrounding community and organizations in supporting the sport sector via budget and kind (i.e sport facilities and equipment) and weakness of sport professionals. But Organization by themselves they have their own a plan and aim to serve the local community in different sector including Sport. In respect with the society and organization participation in the fulfilment of sport facilities and equipments David C. Watt (1998) discussed that, the enormous range of sports facilities makes them almost too many to mention sport of some nature can take place in almost any indoor or outdoor facility. Many sports demand highly sophisticated facilities but others can take place, especially at the participation level, in the most rudimentary area with nothing but the bare essential equipment, or even adapted or invented equipment which approximates to the ideal. The aim of the sponsor is to exploit sport passion, excitement and emotions to reinforce its image, create visibility and increase brand loyalty" (Zagnoli \& Radicchi, 2011) ${ }^{[20]}$. As Jobber (2007) ${ }^{[21]}$. States that there are five major principals of sponsorship objective. These Objectives include creating promotional opportunities, improving community relations, Fostering favourable brand and company associations, creating entertainment Opportunities and gaining publicity.

\section{Conclusion}

The current study mainly investigates to assess the Determinants of accessibility of Sport facilities and equipment the Case of Dessie City administration. According to this study finding, factors that limited the availability of support facilities and equipments in one country can be seen in the following four categories. They are Budget issues, capability of sport administrators to mobilize the community, sport facilities ownership issues and surrounding opportunities. Whether it is for maintenances as well as for fulfilment of sport facilities and equipments, acquiring the necessary funds through allocated budget or community mobilization is essential. However, regarding with the government funds allocated for the above mentioned purpose, as investigated in the current research, it can be concluded there is no allocated fund or it is immaterial to fulfil the required sport facilities and equipments. It is reported that there is no a budget allocated at sub cities level for the fulfilment of sport facilities and equipments.

Similarly, the funds rose to finance the fulfilments of sport facilities and equipments is very low due to the lower effort and capability of sport officers and administrators. Though there is in some extent sport officers and administrators' role in fulfilling sport facilities and equipments, majority of the respondents including sport officers and administrator believe that sport administrators and officers work as it is expected from them to mobilize the community in general and business mans in the city in particular to raise the required fund in order to fulfil sport facilities and equipments in the study area.

The other factor for the fulfilment of sport facilities and equipments in the study area is the availability of sponsoring bodies and the society interest to support the sport. In fact, it by itself is not considered as good opportunity unless sport officers and administrators. Considering the effort of sport administrators/leaders to mobilize the surrounding community to support sport activities, the availability of sponsoring bodies as well as the society interest is considered as one opportunity in acquire the required funds to fulfil as well as repair sport facilities and equipments. Due to that the availabilities of such opportunities are considered one factor in the fulfilment of sport facilities and equipments in one town. As the result of the research shows the availability of such opportunities is moderate. In this regard as respondents replied that, in some extent there is a community interest for the fulfilment of sport facilities and equipments.

Regarding to the priority factors that affect the accessibility of sport facilities and equipments as the officials of sub city of replayed via interview indicated that, unavailability of allocated budget is a crucial determining factor for the accessibility of sport facilities as well as sport equipments as compared to others. The study also shows that, the fences of most of sport facilities are not properly protected and managed by the local community and sport offices. And $63.6 \%$ of the sport fields found in Dessie city administration have ownership problem. 


\section{Recommendations}

On the bases of the finding of the study, the researcher forwarded the following points as a recommendation:

- To fulfil sport facilities and equipment as well as maintenance and improvement purpose of them budget is one issue for Dessei city administration in general and in sub cities of the city in particular. Hence, an appropriate budget has to be allocated for the above mentioned purpose in accordance with the annual activity plan of the sub cities. A due attention has to be given for the fulfilment of sport facilities and equipment because the fulfilment of support facilities is a significant determinant for the participation of sport families. Sport facilities and equipment's are essential for the whole parts of a community, (Cindy, K., Jeffrey, G. and Petersen, 2006) [5]. Sports facilities are commonly believed to have a positive influence on attendance levels of participants, (Hill \& Green, 2000; Dale et al., 2005) ${ }^{[10]}$.

- The effort of sport administrator and workers in mobilizing the surrounding community to support on the fulfilment of sport facilities and equipment is vital. However, the current study revealed that the effort as well as the competency of sport administrators in raising a fund from the community to fulfil sport facilities and equipment is levelled as very low. Hence the concerned bodies have to build the capacity of the sport administrators to work with surrounding community and different organization in generating income for the development of sport activities

- An investigation also shows that, the fences of most $(63.6 \%)$ of sport facilities (i.e fields, courts) are not manage properly. They are being destroyed by the community. The people who pass by their use the fences of sport fields for urine. Hence, the concerned body has to give a due attention for the protection of sport facilities. Furthermore, awareness about sport facilities sense of ownership has to be created among the community so that the community itself will protect the resources there. The involvement of local communities in the identification of relevant opportunities can ensure appropriate provision, a sense of ownership, and cooperation and all of which can contribute to the success and sustainability of program or sport.

- Similarly, it is discussed in the finding of this study is that, most of the sport facilities found in Dessie cities have ownership problem. Hence the concerned sub city office has to solve the problem in cooperation with the city municipal. This will have an encouragement for the surrounding communities to sport the sport activities.

\section{Acknowledgments}

Sincere appreciation is expressed to the following individual who helped me in the compiling of this research, their advice, guidance, and comments proved most beneficial.

First of all, I would like to thank my almighty God for whom nothing and impossible. As well I would like to express my sincere gratitude and appreciation to my wife w/ro Marshet Abate for her moral support throughout this research output

I would also like to thank those Dessie city Administration sports administrator and workers, Sport funs, sport participants, coaches and players for their support in data collection period. At last but not least I am very grateful thanks to everyone who participate in this study for sharing their personal experience and knowledge.

\section{References}

1. Aaker, Day. Doing management research, A comprehensive Guide, London, Thousand oaks New Delhi 1990.

2. Adedeji JA. Evaluation of intramural sports programme and programming in Nigeria Colleges of Education, Journal of Nigeria academy of sports administration 1990;6:34-55.

3. Borough P. Weymouth Council of sport facilities strategy 2014.

4. Cohen. Management and organization...co Language English LSBN-10 1989.

5. Cindy K, Jeffrey G, Petersen. Journal of physical education, recreation and dance 2006.

6. Dawson A, Dejionghe T, Downward. Sport economics theory, evidence and policy 2011.

7. Delve, Temmermen. Sport in developed country, South America, Toronto, Canada 2007.

8. Diejomaoh EO, Akarah E, Tayire OF. Availability of Facilities and Equipment for Sports Administration at the Local Government Areas of Delta State, Nigeria 2015.

9. David Watt C. Sports management and administration. New York: Rout ledge, Taylor and Francis 2003.

10. Hill B, Green BC. Repeat attendance as a function of involvement, loyalty, and the Sport scope across three football context. Sport management review 2000;3:145162.

11. Higham J, Hinch T. Sport tourism development, Britain 2003.

12. Jackson SL. Research method and statistics: critical thinking approach $3^{\text {rd }}$ edition. Belmont, CA: Wadsworth 2009.

13. Jobber David. Principles and Practice of Marketing. 5thed 2007.

14. Judith GL. Importance of availability of good sport facilities, Rutledge Amazon 1998.

15. Kothari CR. Research methodology, methods, and techniques. $2^{\text {nd }}$ edition. New Delhi: New Age international Ltd 2007.

16. MRiera. Advantage of having sport Equipment in your cities 2016.

17. Ministry of Sport and Youth Affairs. National sport policy of Trinidad and Tobago 2002.

18. Nteere JS, Ringtaugu EG. Availability and adequacy of sport facilities and Equipment in selected secondary school in Kenya 2011.

19. Ojeme EO. Standard sport facilities, equipment and new challenges 21th century and Sport development in Nigeria, Abuja federal ministry of sports and social development 2000.

20. Sport Scotland Caledonia house. Community use of sport facilities work book, South Gyle 2000.

21. Sekaran U. Research methods for business, fourth edition, southern Illinois University at Carbondale, Johnwiley and Soncinc 2003.

22. Zagnoli P, Radicchi E. Sport marketing e nuovi media. Milan, Italy: Franco Angeli 2011. 